\title{
Genetic relatedness and molecular characterization of multidrug resistant Acinetobacter baumannii isolated in central Ohio, USA Vijaya B Srinivasan ${ }^{1}$, Govindan Rajamohan ${ }^{1,2}$, Preeti Pancholi ${ }^{3}$, Kurt Stevenson ${ }^{4,5}$, Daniel Tadesse ${ }^{1}$, Prapas Patchanee ${ }^{1}$, Mario Marcon ${ }^{6}$ and Wondwossen A Gebreyes*1
}

Address: ${ }^{1}$ Department of Veterinary Preventive Medicine, College of Veterinary Medicine, Columbus, Ohio, USA, ${ }^{2}$ Institute of Microbial Technology, CSIR, Sector 39A, Chandigarh, India, ${ }^{3}$ Department of Pathology, College of Medicine, The Ohio State University, Columbus, Ohio, USA, ${ }^{4}$ Department of Internal medicine, Division of Infectious Diseases, College of Medicine, The Ohio State University, Columbus, Ohio, USA, ${ }^{5}$ Department of Clinical Epidemiology, The Ohio State University Medical Center, Columbus, Ohio, USA and ${ }^{6}$ Department of Laboratory Medicine, Nationwide Children's Hospital, Columbus, Ohio, USA

Email: Vijaya B Srinivasan - vijirmohan@gmail.com; Govindan Rajamohan - rajamohan.3@osu.edu; Preeti Pancholi - preeti.pancholi@osumc.edu; Kurt Stevenson - kurt.stevenson@osumc.edu; Daniel Tadesse - tadesse.5@osu.edu; Prapas Patchanee - patchanee.1@osu.edu; Mario Marcon - mmarcon@nationwidechildren.org; Wondwossen A Gebreyes* - gebreyes@cvm.osu.edu

* Corresponding author

Published: 17 June 2009

Annals of Clinical Microbiology and Antimicrobials 2009, 8:2I doi:I0.| |86/|476-07| I-8-2I
Received: 22 December 2008

Accepted: 17 June 2009

This article is available from: http://www.ann-clinmicrob.com/content/8/I/2।

(c) 2009 Srinivasan et al; licensee BioMed Central Ltd.

This is an Open Access article distributed under the terms of the Creative Commons Attribution License (http://creativecommons.org/licenses/by/2.0), which permits unrestricted use, distribution, and reproduction in any medium, provided the original work is properly cited.

\begin{abstract}
Background: Over the last decade, nosocomial infections due to Acinetobacter baumannii have been described with an increasing trend towards multidrug resistance, mostly in intensive care units. The aim of the present study was to determine the clonal relatedness of clinical isolates and to elucidate the genetic basis of imipenem resistance.
\end{abstract}

Methods: A. baumannii isolates $(n=83)$ originated from two hospital settings in central Ohio were used in this study. Pulsed-field gel electrophoresis genotyping and antimicrobial susceptibility testing for clinically relevant antimicrobials were performed. Resistance determinants were characterized by using different phenotypic (accumulation assay for efflux) and genotypic (PCR, DNA sequencing, plasmid analysis and electroporation) approaches.

Results: The isolates were predominantly multidrug resistant (>79.5\%) and comprised of thirteen unique pulsotypes, with genotype VII circulating in both hospitals. The presence of bla $\mathrm{OXA}_{23}$ in I3\% $(\mathrm{II} / 83)$ and IS $\mathrm{Abal}_{\text {I }}$ linked bla $\mathrm{OXA}_{\mathrm{O}-66}$ in $79.5 \%$ (66/83) of clinical isolates was associated with high level imipenem resistance. In this set of OXA producing isolates, multidrug resistance was bestowed by $b_{\mathrm{ADC}-25}$, class I integron-borne aminoglycoside modifying enzymes, presence of sense mutations in gyrA/parC and involvement of active efflux (with evidence for the presence of $a d e B$ efflux gene).

Conclusion: This study underscores the major role of carbapenem-hydrolyzing class $D \beta$ lactamases, and in particular the acquired OXA-23, in the dissemination of imipenem-resistant $A$. baumannii. The co-occurrence of additional resistance determinant could also be a significant threat. 


\section{Background}

Acinetobacter baumannii is a rapidly emerging nosocomial pathogen and causes severe infections that include bacteremia, pneumonia, meningitis, urinary tract and wound infections [1]. It has now become a major cause of hospital-acquired infections worldwide due to its remarkable propensity to rapidly acquire resistance determinants to a wide range of antibacterial agents [2]. Of note, increasing resistance to carbapenems has been observed worldwide in the past decade [3]. Carbapenemase production is the most described mechanism of resistance to carbapenems [4]. The carbapenemases in A. baumannii have belonged to the $b l a_{\text {OXA-23-r }} b l a_{\text {OXA-24- }}$ and $b l a_{\text {OXA-58- }}$ type class $\mathrm{D}$ family of serine $\beta$-lactamases and IMP/VIM class B metallo- $\beta$ lactamases $[3,4]$. The upstream of OXA type class D carbapenemases in Acinetobacter is often associated with insertion sequence (IS), ISAba1 and other IS may modulate the expression and transfer of OXA-type carbapenemase genes [5-10]. IS are mobile genetic elements known to affect the evolutionary pattern of bacterial genomes. Upon integration, IS elements may cause DNA insertions/ deletions, chromosomal rearrangement, modulate the expression of neighbouring genes and, thereby, influence the phenotype of a bacterium [11].

Numerous outbreaks caused by multidrug-resistant (MDR) A. baumannii from different parts of United States are appearing very rapidly [12-16]. One of the most poignant instances is the widespread prevalence of MDR A. baumannii among personnel returning from military operations in Iraq and Afghanistan [17]. The Infectious Diseases Society of America (IDSA) identified A. baumannii among the top seven pathogens threatening our healthcare-delivery system and as a crucial example of unmet medical need [18].

Our phenotypic analysis clearly demonstrated that A. baumannii isolates obtained from different hospitals in central Ohio were resistant to all clinically significant antibiotics, including carbapenems (imipenem). The aim of the present study was to determine the clonal relatedness among clinical isolates and the genetic basis for imipenem resistance. Molecular determinants enabling the imipenem resistant strains to exhibit co-resistance to aminoglycosides and fluoroquinolones from this geographical region were delineated.

\section{Methods}

\section{Study population}

A. baumannii isolates $(\mathrm{n}=83)$ that originated from two sources were investigated. They consisted of isolates from The Ohio State University Medical Center (referred as MC) $(n=47)$ and other central Ohio hospitals retrieved from the Ohio Department of Health (referred as ODH) $(\mathrm{n}=36)$ collected during 2005-2007 time period. These isolates were obtained from different Intensive Care Units (ICU) and non-ICUs in the hospitals. The selection criteria of these strains were based on the heterogeneity in their properties such as, geographic origin, time of isolation, levels of resistance to carbapenems, aminoglycosides and fluoroquinolones, thus excluding multiple isolates of the same strain from one locality. Forty-seven isolates of MC were originally isolated from aspirated sputum (24\%), BAL (17\%), bronchial wash (16\%) and other systems including blood (26\%), wound $(2 \%)$ and urinary infections $(15 \%)$. Thirty-six isolates from $\mathrm{ODH}$ were obtained from bronchial wash (37\%), sputum (33\%), blood (8\%), BAL (12\%) and remaining $10 \%$ from urine and wound. The isolates were obtained from patients belonging to different age groups: $60-90$ years $(n=54)$, $20-50$ years $(\mathrm{n}=28)$ and one isolate from a 15 -year-old. No additional individual patient data was retrieved as it was beyond the scope of this investigation. Institutional Review Board exemption was obtained prior to retrieval of the isolates from the pathogen bank.

\section{Bacterial isolation and identification}

The 83 A. baumannii clinical isolates were identified by using the Vitek $2^{\circledast}$ automated instrument ID system (BioMérieux, Marcy l'Etoile, France), API 20NE system (BioMerieux, Inc) and NUC 45 Identification Panel (MicroScan ${ }^{\mathrm{R}}$, Siemen's Healthcare, Sacramento, CA, USA) and sequencing of the gyrA house keeping gene, as described previously [19].

\section{Minimum Inhibitory Concentration (MIC)}

Susceptibilities of A.baumannii isolates to imipenem, ceftazidime, amikacin, streptomycin, gentamicin, kanamycin, tetracycline, ciprofloxacin and nalidixic acid were tested using broth dilution technique. Multidrug resistance was defined in this analysis as resistance to three or more representatives of the following classes of antibiotics: quinolones (ciprofloxacin and nalidixic acid), extended-spectrum cephalosporins (ceftazidime), aminoglycosides (amikacin, streptomycin, gentamicin, kanamycin), and carbapenems (imipenem). Interpretation was done as per the criteria approved by the Clinical and Laboratory Standards Institute CLSI [20]. E. coli ATCC 25922 was used as a reference strain (control) as recommended.

\section{Pulsed-field gel electrophoresis (PFGE) genotyping}

PFGE was performed according to the Centers for Disease Control and Prevention Pulse Net protocol [21] with minor modifications. Fingerprint images were analyzed by Bionumerics software V. 4.61 (Applied Maths NV, Belgium) using dice similarity index for cluster analysis and the unweighted pair group average (UPGMA) for tree building. All isolates with PFGE banding patterns with a similarity index $>75 \%$ were grouped within the same clus- 
ter. Banding patterns were compared with 3.0\% optimization and $2.5 \%$ band position tolerance.

\section{PCR amplifications and sequence analyses}

Genomic DNA was extracted using DNeasy Tissue kit (Qiagen; Valencia, CA, USA). PCR for evaluating the presence of 13 different $\beta$-lactamases, IS ${ }_{A b a 1}$, IS ${ }_{1133}$, class 1 integrons and its variable region, int2, int3, aphA6, qnrA ${ }_{6}, q n r B_{1-6}$ and $q n r S_{1-2}[22], \operatorname{tet}(A), \operatorname{tet}(B)$ [23], quinolone resistance determining region (QRDR) of gyr $A$, parC, adeB, $a d e R$ and $a d e S$ genes were carried out using specific primers (Table 1). All amplicons were sequenced bidirectionally using CEQ 8000 (Beckman Coulter Instruments Inc., Palo Alto, CA) capillary electrophoresis system and ana- lyzed by BLAST at http://www.ncbi.nlm.nih.gov. To determine the location and orientation of the insertion sequence (IS) element, combination primers specific to both IS $\mathrm{Aba1}_{1}$ and $b l a_{\mathrm{OXA}-66}$ or $b l a_{\mathrm{ADC}-25}$ were used $[24,25]$.

\section{Plasmid analysis}

Plasmid DNA was isolated using alkaline lysis method as described before [26]. Escherichia coli JM109 electrocompetent cells were transformed with 30 ng of plasmid preparations and were screened on LB plates (Difco, BectonDickinson, Sparks, MD) containing different antibiotics, (Sigma, St. Louis, MO): amikacin, streptomycin, gentamicin, kanamycin $(10 \mu \mathrm{g} / \mathrm{ml}$ respectively), imipenem (1 $\mu \mathrm{g} / \mathrm{ml})$, ciprofloxacin $(1 \mu \mathrm{g} / \mathrm{ml})$, nalidixic acid $(30 \mu \mathrm{g} / \mathrm{ml})$

Table I: Primers used for PCR amplification

\begin{tabular}{|c|c|c|c|c|}
\hline \multicolumn{4}{|c|}{ Primer sequence (5' to 3 ') } & \multirow[t]{2}{*}{ Reference } \\
\hline Target gene(s) & Forward & Reverse & Size of amplicon & \\
\hline bla $_{\text {TEM-I }}$ & GCACGAGTGGGTTACATCGA & GGTCCTCCGATCGTTGTCAG & 310 & 14 \\
\hline bla $_{\text {PER-I }}$ & ATGAATGTCATTATAAAAG & TTGGGCTTAGGGCAG & 927 & 14 \\
\hline$b a_{\mid M P}$ alleles $|-2|$ & GTTTATGTTCATACWTCG & GGTTTAAYAAAACAACCAC & 432 & 14 \\
\hline $\mathrm{bla}_{\mathrm{VIM} \text { alleles }}$ & TTTGGTCGCATATCGCAACG & CCATTCAGCCAGATCGGCAT & 500 & 14 \\
\hline bla $_{\mathrm{GIM}}$ & ATATTACTTGTAGCGTTGCCAGC & TTAATCAGCCGACGCTTCAG & 729 & 14 \\
\hline bla $_{\mathrm{SHV}}$ & ATGCGTTATATTCGCCTGTG & TGCTTTGTTATTCGGGCCAA & 753 & 14 \\
\hline bla $_{\text {SIM }}$ & ATGAGAACTTTATTGATTTT & TTAATTAATGAGCGGCGGTT & 741 & This study \\
\hline bla $_{C T X-M}$ & ATGATGACTCAGAGCATTCGCCGCT & TCAGAAACCGTGGGTTACGATTTTCG & 876 & 14 \\
\hline bla $_{\mathrm{ADC}}$ & ATGCGATTTAAAAAAATTTCTTGT & TGGAATACGTTTATTGGTTAACATGA & 1081 & 14 \\
\hline OXA-23-like & TCTGGTTGTACGGTTCAGC & AGTCTTTCCAAAAATTTTG & 606 & 14 \\
\hline OXA-24-like & ATGAAAAAATTTATACTTCC & TTAAATGATTCCAAGATTTTC & 828 & 14 \\
\hline OXA-5I-like & ACAGAARTATTTAAGTGGG & GGTCTACAKCCMWTCCCCA & 880 & 14 \\
\hline bla $_{O X A-58}$ & $\begin{array}{l}\text { ATGAAATTATTAAAAATATTGAGTTTA } \\
\text { G }\end{array}$ & TTATAAATAATGAAAAACACCCAAC & 843 & 14 \\
\hline $\mid S_{\text {Abal }}$ & ATGCAGCGCTTCTTTGCAGG & AATGATTGGTGACAATGAAG & 393 & 14 \\
\hline$I_{1133}$ & ATGACACATCTCAATGAGTTATAT & TTAACACGAATGCAGAAGTTGATG & 543 & 14 \\
\hline ISAb-FI/OXA/IS-R & AGTTGCACTTGGTCGAATGAA & CCATAGCTTTGTTGAGTTTGG & 540 & 22 \\
\hline ISAb-F2/OXA/IS-R & TTGAAAATACGCGCTTGACAGA & CCATAGCTTTGTTGAGTTTGG & 1104 & 22 \\
\hline ISAb-F3/OXA/IS-R & CTCTGTACACGACAAATTTCAC & CCATAGCTTTGTTGAGTTTGG & 1384 & 22 \\
\hline $\mid S_{\text {Aba I- }}$ ampC-UP & GACCTGCAAAGAAGCGCTGCATA & TTGGTTCTTTTAAACCATATACC & 1502 & This study \\
\hline intl I $5^{\prime} \mathrm{CS}$ & GACGATGCGTGGAGACC & CTTGCTGCTTGGATGCC & 300 & 25 \\
\hline intll 3 'CS & ATCGCAATAGTTGGCGAAGT & GCAAGGCGGAAACCCGCC & 800 & 25 \\
\hline Variable region & GGCATCCAAGCAGCAAGC & AAGCAGACTTGACCTGAT & Variable & 25 \\
\hline int 12 & ACGATGCCTGCTTTTTGTACGGCTGC & CCGTCTATCCTGCTTGCACGATGCA & 962 & This study \\
\hline intl3 & $\begin{array}{l}\text { TCAGCCGGGCGACAAGTGCAAGGCC } \\
\text { A }\end{array}$ & ATGAACAGGTATAACAGAAAT & 1041 & This study \\
\hline aphA6 & ATGGAATTGCCCAATATTATTC & TCAATTCAATTCATCAAGTTTTA & 780 & 14 \\
\hline tet $\mathrm{A}$ & GCGCGATCTGGTTCACTCG & AGTCGACAGYRGCGCCGGC & 164 & 36 \\
\hline tet $B$ & TACGTGAATTTATTGCTTCGG & ATACAGCATCCAAAGCGCAC & 206 & 36 \\
\hline qnrAl to qnrA6 & AGAGGATTTCTCACGCCAGG & TGCCAGGCACAGATCTTGAC & 661 & 37 \\
\hline qnrBI to qnrB6 & GGMATHGAAATTCGCCACTG & TTTGCYGYYCGCCAGTCGAA & 562 & 37 \\
\hline qnrSI to qnrS2 & GCAAGTTCATTGAACAGGGT & TCTAAACCGTCGAGTTCGGCG & 605 & 37 \\
\hline gyrA (QRDR) & AAATCTGCCCGTGTCGTTGGT & GCCATACCTACGGCGATACC & 285 & 14 \\
\hline $\operatorname{parC}(\mathrm{QRDR})$ & AAAAATCAGCGCGTACAGTG & CGAGAGTTTGGCTTCGGTAT & 276 & 14 \\
\hline adeB & GGATTATGGCGACAGAAGGA & AATACTGCCGCCAATACCAG & 981 & This study \\
\hline adeR & ATGTTTGATCATTCTTTTTCTTTTG & TTAATTAACATTTGAAATATG & 687 & 14 \\
\hline ades & TTCAACAAGAAGATTGGACC & CTTGCTCAATACGACGG & 114 & 28 \\
\hline
\end{tabular}

a $\mathrm{Y}=\mathrm{C}$ or $\mathrm{T} ; \mathrm{M}=\mathrm{A}$ or $\mathrm{C} ; \mathrm{R}=\mathrm{A}$ or $\mathrm{G} ; \mathrm{W}=\mathrm{A}$ or $\mathrm{T} ; \mathrm{K}=\mathrm{G}$ or $\mathrm{T} ; \mathrm{H}=\mathrm{A}$ or $\mathrm{C}$ or $\mathrm{T}$.

$\mathrm{b} Q R D R$, quinolone resistance-determining region. 
and tetracycline $(10 \mu \mathrm{g} / \mathrm{ml})$. Transformants were restreaked on identical plates for confirmation.

In vitro studies to elucidate the occurrence of active efflux The accumulation of ciprofloxacin was examined as described previously [27]. The efflux pump inhibitors used in this study were carbonyl cyanide $m$-chlorophenylhydrazone (CCCP), verapamil and reserpine, (Sigma, St. Louis, MO); to a final concentration of $25 \mu \mathrm{g} / \mathrm{ml}$. The growth inhibition assay was done as described previously with minor modifications [28]. A. baumannii cultures at mid log phase $\left(\mathrm{OD} 600_{\mathrm{nm}}=0.2\right.$ ) were inoculated into LB broth containing antimicrobials at different concentrations either alone or with inhibitor. The extent of growth inhibition was analyzed by measuring the absorbance at $600 \mathrm{~nm}\left(\mathrm{OD} 600_{\mathrm{nm}}\right)$ after $6 \mathrm{hrs}$ of incubation at $37^{\circ} \mathrm{C}$. All data from the in vitro kinetics and flourimetric assay are presented as means \pm the standard error of the mean and calculation of the standard deviation was performed in Excel (Microsoft, USA). The statistical significance was determined using the paired Student's $t$-test. P values of < 0.05 were considered significant.

\section{Accession numbers}

The sequences of $a a d B$, aadB-aadA2, aacC1-orfX-orfX'aadA1, aacA4-catB8- aadA2, bla $a_{\mathrm{OXA}-66^{\prime}}, b l a_{\mathrm{TEM}-1}, b l a_{\mathrm{ADC}-25}$, aphA6, $\mathrm{IS}_{\mathrm{Aba} 1}, b l a_{\mathrm{OXA}-23}, \mathrm{QRDR}$ of gyrA and parC genes obtained in this study were deposited in the GenBank database under the following accession numbers: EU977565, EU977566, EU977567, EU977568, EU977569, EU977570, EU977571， EU977572, EU977573, EU977574, EU977575 and EU977576 respectively.

\section{Results \\ Antimicrobial susceptibility and genotypic diversity}

In this study, about $79.5 \%$ (66/83) were multi-drug resistant (MDR). Among these, 62 were resistant to ceftazidime and 66 were resistant to imipenem. The imipenem resistant isolates $(66 / 83)$ were also resistant to kanamycin, amikacin, gentamicin, streptomycin, tetracycline, ciprofloxacin and nalidixic acid. Overall, 7\% (6/83) were found resistant only to chloramphenicol and remaining $14.5 \%(12 / 83)$ isolates were pan-susceptible (See Additional file 1$)$.

To determine the extent of genotypic diversity among the MDR A. baumannii, PFGE was conducted and the isolates were clustered into thirteen major genotypes (I to XIII) at $75 \%$ genotypic similarity threshold. Profiles of randomly selected isolates $(n=31)$ are depicted in Figure 1 . Though their genotypes were diverse, majority of the isolates exhibited increased resistance to $\beta$-lactams, aminoglycosides and quinolones. Genotype VII was found as the most common cluster type (28/83) that was found circu- lating in hospitals regardless of origin: 16 isolates from MC (19\%) and 12 from ODH (14\%).

\section{Molecular determinants for $\beta$-lactam resistance}

Eleven imipenem resistant isolates (13\%) contained the acquired carbapenem hydrolyzing class $\mathrm{D} \beta$-lactamase (CHDLs) gene bla $a_{\text {OXA-23 }}$ [GenBank: EU977574] (See Additional file 1). The other CHDLs including $b l a_{\text {OXA-24 }}$ and $b l a_{\text {OXA-58 }}$ like genes could not be identified in this study. Sixty-six imipenem resistant isolates (79.5\%) carried $\mathrm{IS}_{A b a 1}$ genetic element preceding the naturally occurring carbapenemase $b l a_{\text {OXA-66, }}$ a $b l a_{\text {OXA-51 }}$ like gene [GenBank: EU977573, EU977569] (See Additional file 1). However IS $_{1133}$ was not found in this collection.

The cephalosporinase $b l a_{\mathrm{ADC}-25}$ was detected in 62 ceftazidime resistant isolates and PCR mapping indicated that $\mathrm{IS}_{A b a 1}$ was not present upstream to the cephalosporinase identified in this study [GenBank: EU977571] (See Additional file 1).

The class A $\beta$-lactamase $b l a_{\mathrm{TEM}-1}$ was found in $37 \%$ of the clinical isolates [GenBank: EU977570] (See Additional file 1$)$. The other reported metallo- $\beta$-lactamases such as $b l a_{\mathrm{SIM}^{\prime}}, b l a_{\mathrm{IMP}}, b l a_{\mathrm{VIM}}, b l a_{\mathrm{GIM}}$ and other $\beta$-lactamases including $b l a_{\mathrm{SHV}}, b l a_{\mathrm{CTX}-\mathrm{M}^{\prime}} b l a_{\mathrm{PER}^{\prime}}$ were not detected in any of our isolates.

\section{Molecular determinants for aminoglycoside resistance}

Class 1 integrons were found in $40 \%(33 / 83)$ of the isolates. The length of the amplicons ranged between 0.75 to $2.5-\mathrm{kb}$. The $0.75-\mathrm{kb}$ amplicon found in a single isolate carried an aminoglycoside modifying enzyme (AME) aadB [Genbank: EU977565]. The 1.6-kb amplicon detected in three isolates with Type I PFGE profile, AC0047, AC0050 and AC0053 harboured $a a d B$ and aadA2 gene cassettes [GenBank: EU977566].

The 2.3-kb amplicon found in 26 isolates carried aacA4catB8-aadA2 gene cassettes [GenBank: EU977568]. In this study, 33\% (28/84) of the isolates belonged to PFGE type VII. Of these, 24\% (20/84) harboured Class 1 integron with aacA4-catB8-aadA1 variable region whereas the remaining $9 \%(8 / 84)$ isolates did not harbour integron.

A 2.5-kb amplicon obtained in three clinical isolates, AC0023, AC0024 and AC0039 carried aacC1-orfX-orfX'aadA1 gene cassettes [GenBank: EU977567] (Figure 2).

The integrases intI 2 and intI3 were not found in any of the isolates. The aminoglycoside resistance gene aphA6 was found in $18 \%$ of the isolates (15/83) that exhibited different MDR profiles [GenBank: EU977572] (See Additional file 1). 


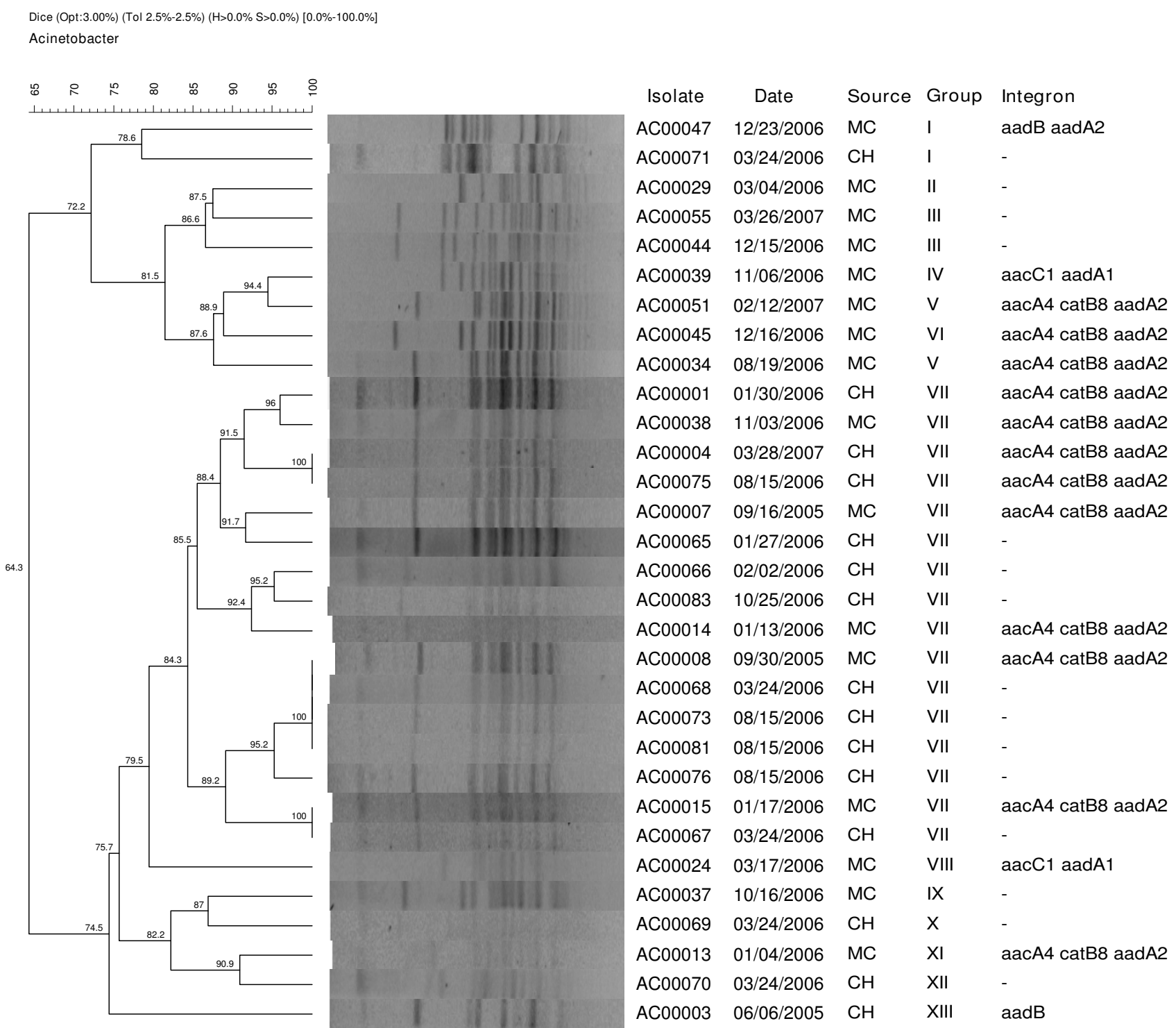

Figure I

PFGE profiles of selected strains. A. baumannii isolates representing various resistance profiles from different hospitals and different units were genotyped. Figure is the representation of PFGE fingerprints of thirty one selected isolates. Thirteen genotypes (Group I to XIII) were identified in this study. The percentage of similarities was determined by the Dice's coefficient and UPGMA clustering. Major clusters were formed at the $75 \%$ similarity level. * Source abbreviations are MC (Ohio State University Medical Center) and $\mathrm{CH}$ (All central Ohio isolates derived from the State Public Health laboratory). The various ICUs in MC include Ross Heart hospital, James Cancer Hospital, Rhodes and Doans hospital and the Emergency Department.

\section{Plasmid carriage and resistance conferred by plasmids}

Plasmids were found in 66 clinical isolates. Plasmids from strains belonging to 13 different pulsotypes were transformed into E. coli JM109 and colonies were obtained only on tetracycline containing LB plate. Though the size of transformed plasmids (originally obtained from A. baumannii isolates exhibiting various pulsotypes) in the obtained colonies were different (which was 5-9 kb), it was interesting to note that they all harboured tet(B) efflux gene (See Additional file 1).

Plasmid borne quinolone resistance $q n r$ genes $\left(q n r A_{1-6}\right.$ $q n r B_{1-6}$ and $q n r S_{1-2}$ ) could not be identified in this study. 


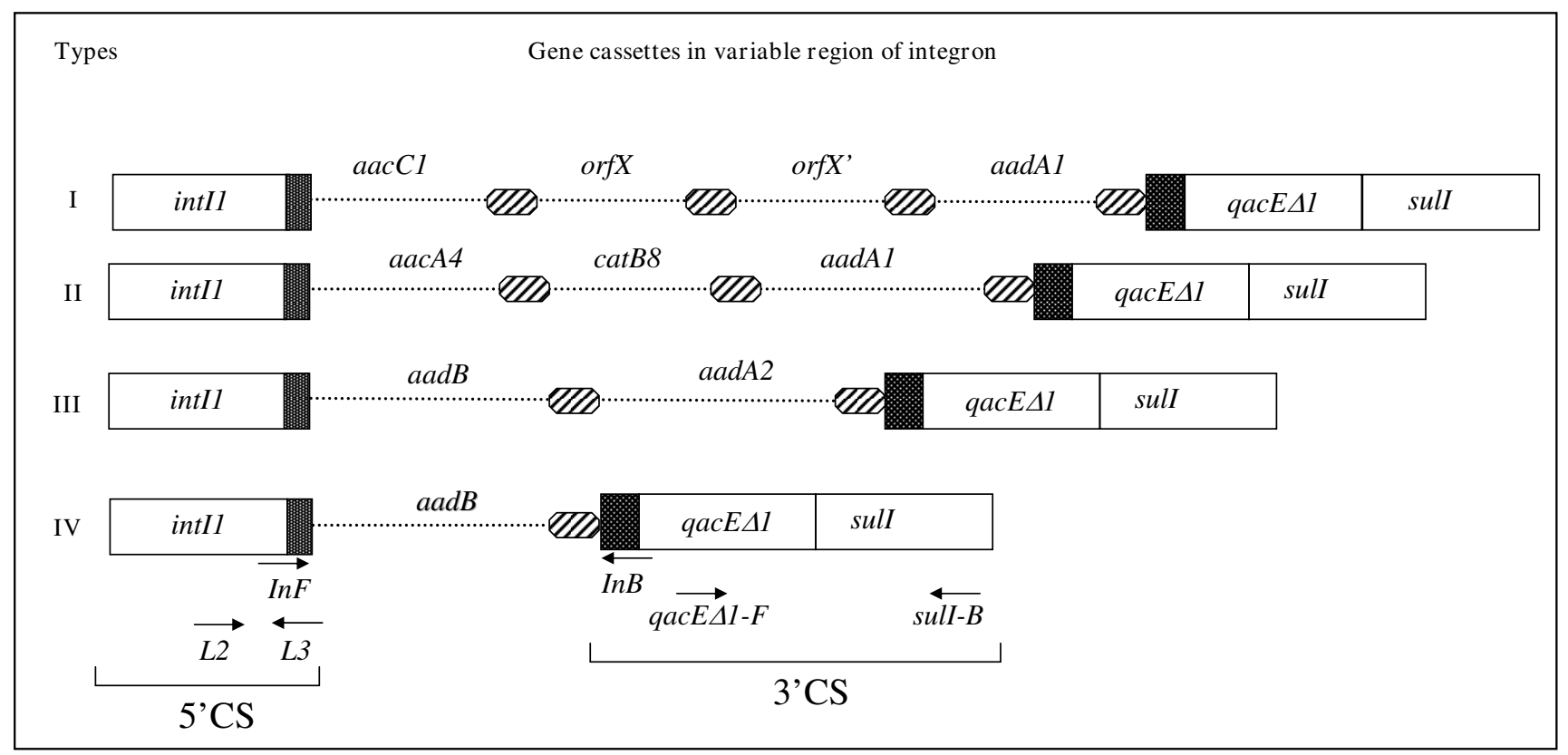

Figure 2

Schematic representation of different types of gene cassettes identified in the Class I integrons in $A$. baumannii strains. Dotted lines represent the gene cassettes, oval circles the 59-base elements. The attl recombination site is shown by the hatched box. Locations of the $5^{\prime} C S$ and $3^{\prime} C S$ of class I integrons and those of the primer pairs, qacEAI-F, SullB and in-F $\left(5^{\prime} C S\right)$, in- $B\left(3^{\prime} C S\right)$, are shown in the bottom panel. Different types of variable region were found in our collection of isolates: Type I: accCI-orfX-orfX'-aadAI; $n=3$, Type II: aacA4-catB8-aadAI, $n=26$, Type III: aadB-aadA2; $n=3$ and Type IV: aadB; $n=1$. accCl (3-N-aminoglycoside acetyltransferase) and aadB (2'-O-adenylyltransferase) confers gentamicin resistance, aadA I and aadA2 (adenyltransferase) confers resistance to spectinomycin and streptomycin, aacA4 (6'- $\mathrm{N}$-acetyltransferase) confers resistance to amikacin, netilmicin and tobramycin, catB8 (chloramphenicol acetyltransferase) confers resistance to chloramphenicol. The diagram was not drawn to scale.

\section{Characterization of quinolone resistance}

In this study, $79.5 \%$ of the nalidixic acid and ciprofloxacin resistant isolates (66/83) (See Additional file 1) harboured sense mutations (Serine to Leucine) at the $83^{\text {rd }}$ and $80^{\text {th }}$ positions in $g y r A$ and parC QRDR respectively [GenBank: EU977575 and EU977576] (See Additional file 1). Additional sense mutations could not be detected elsewhere in these target genes (data not shown).

To elucidate the role of active efflux [27] ciprofloxacin accumulation studies were performed, and analysis indicated that accumulation of ciprofloxacin at steady state was higher in sensitive strains, which was 2.0 to 2.5 times greater than the amount in MDR strains. Addition of CCCP $(25 \mu \mathrm{g} / \mathrm{ml})$ resulted in the restoration of the fluorescence intensity in MDR strains, eventually increasing its level comparable to that of the sensitive strain (Figure 3). Growth inhibition assay also supported the findings of the CCCP mediated inhibition of ciprofloxacin and nalidixic acid efflux in MDR isolates (Figure 4). Addition of CCCP drastically reduced the MIC for ciprofloxacin in 66 MDR isolates clearly indicating the role of efflux mecha- nism in conferring quinolone resistance (See Additional file 1).

Specific PCR assays demonstrated that 53\% (44/83) of the isolates had the transporter gene adeB [29] (See Additional file 1); response regulator $a d e R$ and its cognate kinase adeS. Though 66 strains were quinolone resistant, the adeB efflux gene was found in 44 isolates only, this observation indicates that other efflux systems could be involved in mediating quinolone resistance. Single point mutations in adeR (Pro116 $\rightarrow$ Leu) and adeS (Thr153 $\rightarrow$ Met) known to cause AdeABC constitutive overexpression [30] were not identified in this study.

\section{Discussion}

The study presented here describes the first hospital based outbreak of imipenem resistant $A$. baumannii isolates producing the carbapenem hydrolyzing oxacillinase $b l a_{\text {OXA-23 }}$ in central Ohio. OXA-23 producers have been identified as sources of nosocomial outbreaks worldwide, including the United States $[1,12,13,16]$. Acquired $b l a_{\text {OXA-23 }}$ gene is known to be located in peculiar transposon structures, 


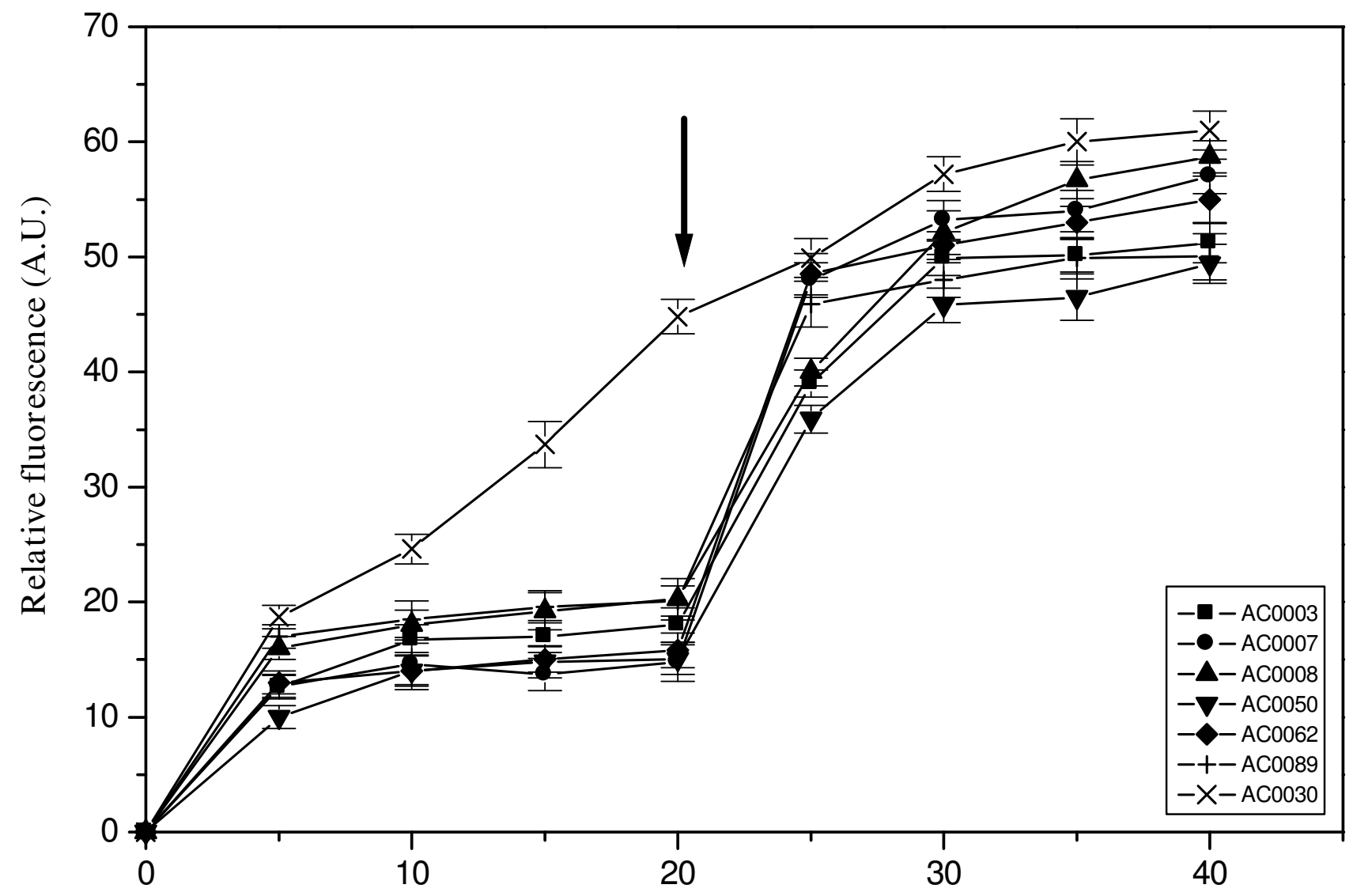

Time of incubation in minutes

\section{Figure 3}

Accumulation studies with ciprofloxacin. The fluorescence of the supernatant was measured with spectroflourimeter (LS 55 Fluorescence Spectrometer, 120 V, Perkin-Elmer model) at an excitation $275 \mathrm{~nm}$ and emission $440 \mathrm{~nm}$ for ciprofloxacin. The results for six representative MDR strains, namely, AC0003, AC0007, AC0008, AC0050, AC0062, AC0089 and one sensitive strain AC0030 are shown here. The graphs reflect the difference in fluorescence displayed by the bacterial cell in the presence and absence of efflux pump inhibitor CCCP. The arrow indicates the time of addition of CCCP. All experiments were carried out at least three times.

namely, Tn2006 (ISAba1 linked) and Tn2007 (ISAba4 linked) $[8,9,11,31]$. Of note, the origin of $b l a_{\text {OXA-23 }}$ was recently identified as the chromosome of Acinetobacter radioresistens, a commensal species of the human skin [32]. In this study, 11 out of 66 imipenem-resistant isolates harboured bla $a_{\mathrm{OXA}-23}$ like gene. Attempts to transfer carbapenem resistance by electroporation of plasmid DNA from $b l a_{\text {OXA-23 }}$ positive isolates were unsuccessful, indicating the probable chromosomal location of this gene.

Numerous reports on $A$. baumannii clinical isolates harbouring CHDLs OXA-58, OXA-40 and OXA-24 in the United States reflect their emergence as important carbapenemases $[13,14,16]$; however, they could not be detected in this set of isolates. Also, as demonstrated these A. baumannii clinical isolates (79.5\%) possessed the chromosomal-encoded oxacillinase gene $b l a_{\text {OXA-66 }}$ that encodes a $\beta$-lactamase known to confer carbapenemase properties $[5,6]$. Multiple copies of ISAba1 are present in most isolates of Acinetobacter spp. [11]. It serves an important role as a 'mobile promoter' [33]. As evidence of this role, we found ISAba1 immediately upstream of $b l a_{\text {OXA-66 }}$ gene in 66 imipenem resistant isolates. More than 25 varieties of AmpC $\beta$-lactamases that share 94\% protein sequence identity have been described for Acinetobacter spp. so far [34]. The oxyimino- $\beta$-lactam resistance seen in these $A$. baumannii strains is attributed to the presence of $b l a_{\mathrm{ADC}-25}$. In this current study, gene cassettes including aacA4-catB8aadA1 and aacC1-orfX-orfX'-aadA1 were predominantly 
A)

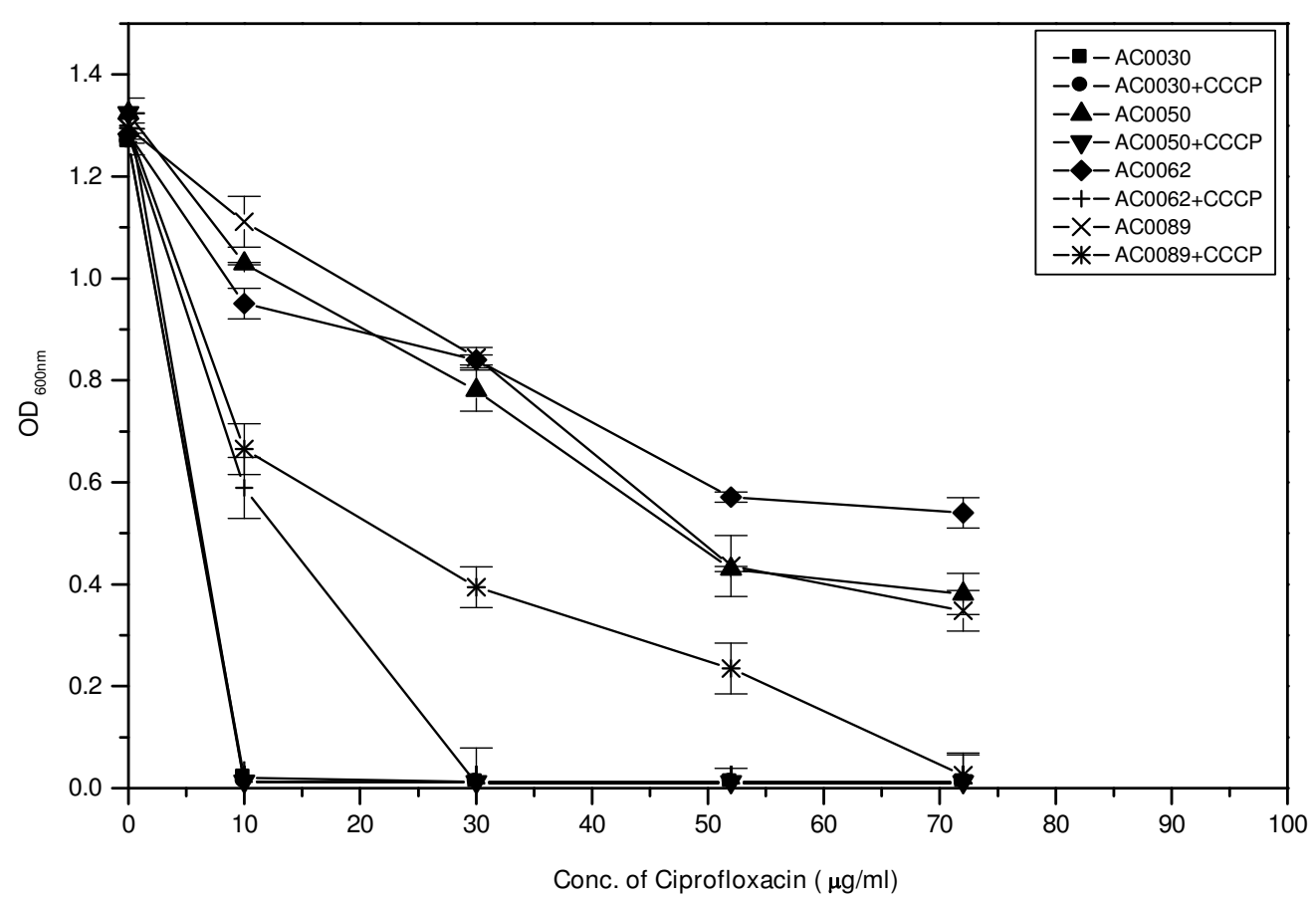

B)

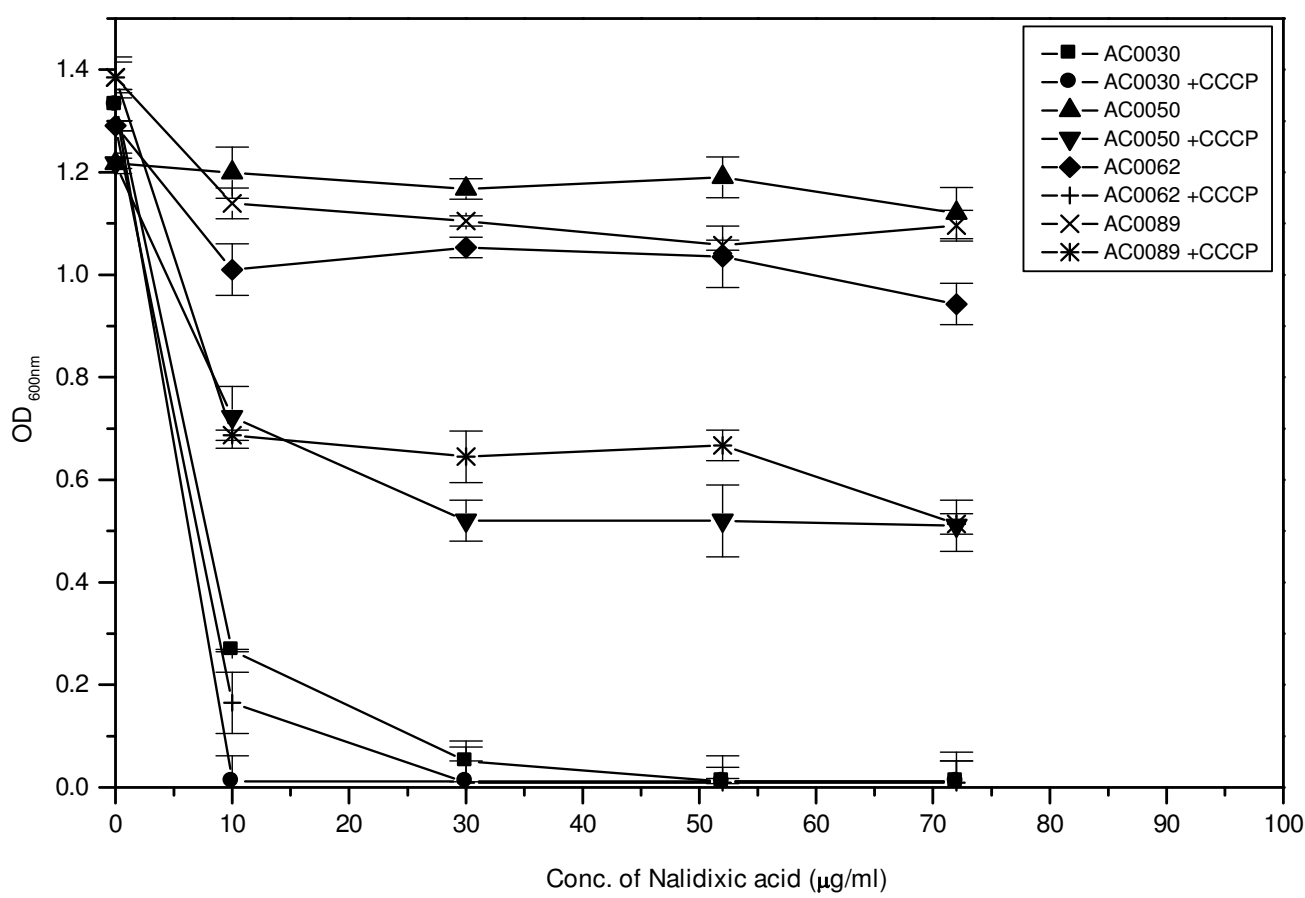

Figure 4

in vitro analysis of growth kinetics. The ability of different MDR clinical isolates namely AC0050, AC0062, AC0089 and sensitive strain AC0030, to grow in the presence of different concentrations of ciprofloxacin (A), nalidixic acid (B), either alone or in the presence of $25 \mu \mathrm{g} / \mathrm{ml}$ of CCCP was monitored in LB broth using a spectrophotometer. Range of results obtained for duplicate experiments are shown by error bars. 
found. Notably, so far these groups of cassettes are reported only in two international lineages, called European clones I and II [35-37]. Given the very high rate of quinolone resistance, this class is unlikely to have any clinical role in the treatment of MDR A. baumannii in central Ohio hospitals.

\section{Conclusion}

Despite the increased frequency of multidrug resistance in A. baumannii in the United States, there exists a relative paucity of information regarding antimicrobial resistance in this Gram negative bacillus from central Ohio. The identification of $b l a_{\text {OXA-23 }}$ and ISAba 1 associated $b l a_{\text {OXA-66 }}$ genes in this study confirms the wide geographical distribution of carbapenemases among A. baumannii as well as their parallel appearance in outbreak strains. The experience with these MDR isolates suggested that surveillance for multidrug resistant $A$. baumannii should be maintained and careful infection control measures and cautious use of antibiotics must be promoted.

\section{Competing interests}

The authors declare that they have no competing interests.

\section{Authors' contributions}

VBS, GR, PP and DT performed the experiments, analyzed the data and drafted the paper. PP, KS, MM provided the strains, related clinical informations and susceptibility data. WG designed the idea, strategies to execute them, finalized the manuscript and provided intellectual suggestions. We thank all the anonymous reviewers for their fruitful suggestions and helpful comments, which helped us to significantly improve the manuscript.

\section{Additional material}

\section{Additional file 1}

Phenotypic and genotypic characteristics of multidrug resistant clinical isolates of A. baumannii. a MIC for antibiotics are expressed in $\mu \mathrm{g} /$ ml. Abbreviations used for different drugs are: IPM: Imipenem, CAZ: Ceftazidime, KAN: Kanamycin, STR: Streptomycin, GEN: Gentamicin, AMK: Amikacin, CIP: Ciprofloxacin. Interpretation of the results was done using the criteria recommended by the Clinical and Laboratory Standards Institute CLSI [20]. Escherichia coli ATCC 25922 was used for quality control. ${ }^{b} \beta$-lactamases SHV, CTX-M, PER, SIM, IMP, VIM, GIM, OXA-24 like and OXA-58 like were not identified in this study. ${ }^{c}$ The different gene cassettes (Type I to IV; as described in Figure 2) identified in the variable region of class 1 integron. ${ }^{d}$ aminoglycoside phosphotransferase gene. ${ }^{e}$ Reduction in MIC after the treatment of CCCP is given in parentheses. ${ }^{\prime}$ MIC for NAL in strains with both mutations were $>128$ $\mu \mathrm{g} / \mathrm{ml}$. \& Effect of inhibitors reserpine, verapamil $(R / V)$ and CCCP on drug accumulation. +ve sign indicates reduction in MIC of ciprofloxacin on adding CCCP $(25 \mu \mathrm{g} / \mathrm{ml})$ while -ve sign indicates no change in MIC after the addition of either reserpine or verapamil in independent experiments. Efflux pump inhibitors used in this study had no intrinsic antibacterial activity against clinical isolates at the concentration used in the MIC determining experiments. Plasmid borne quinolone resistance qnr genes $\left(\mathrm{qnrA}_{1-6}, \mathrm{qnrB}_{1-6}\right.$ and $\left.\mathrm{qnrS}_{1-2}\right)$ were not found in this study. ${ }^{h}$ Strains that harbored tet $(B)$ had an $M I C>30 \mu \mathrm{g} / \mathrm{ml}$ towards tetracycline, none had tet(A).

Click here for file

[http://www.biomedcentral.com/content/supplementary/14760711-8-21-S1.doc]

\section{Acknowledgements}

This study was funded by The Ohio State University intramural funding to W.A. Gebreyes. We would like to thank technical assistance by members of the Infectious Diseases Molecular Epidemiology Laboratory (IDMEL) team.

\section{References}

I. Dijkshoorn L, Nemec A, Seifert $\mathrm{H}$ : An increasing threat in hospitals: multidrug-resistant Acinetobacter baumannii. Nat Rev Microbiol 2007, 5:939-95I.

2. Gootz TD, Marra A: Acinetobacter baumannii: an emerging multidrug-resistant threat. Expert Rev Anti Infect Ther 2008, 6(3):309-325.

3. Poirel L, Nordmann P: Carbapenem resistance in Acinetobacter baumannii mechanisms and epidemiology. Clin Microbiol Infect 2006, 1 2:826-836.

4. Poirel L, Pitout JD, Nordmann P: Carbapenemases: molecular diversity and clinical consequences. Future Microbiol 2007, 2:50I-5I2.

5. Heritier C, Poirel L, Fournier PE, Claverie JM, Raoult D, Nordmann $P$ : Characterization of the naturally occurring oxacillinase of Acinetobacter baumannii. Antimicrob Agents Chemother 2005, 49:4174-4I79.

6. Figueiredo S, Poirel L, Croize J, Recule C, Nordmann P: In-vivo selection of reduced susceptibility to carbapenems in Acinetobacter baumannii related to ISAbaI-mediated overexpression of the natural bla $a_{\text {oxA-66 }}$ oxacillinase gene. Antimicrob Agents Chemother 2009 in press. doi: I0.1 I 28/AAC.01663-08

7. Heritier C, Poirel L, Lambert T, Nordmann P: Contribution of acquired carbapenem-hydrolyzing oxacillinases to carbapenem resistance in Acinetobacter baumannii. Antimicrob Agents Chemother 2005, 49:3198-3202.

8. Corvec S, Poirel L, Naas T, Drugeon H, Nordmann P: Genetics and expression of the carbapenem-hydrolyzing oxacillinase gene 
bla oxA-23 in Acinetobacter baumannii. Antimicrob Agents Chemother 2007, 5 I: I530-1533.

9. Poirel L, Nordmann P: Genetic structures at the origin of acquisition and expression of the carbapenem-hydrolyzing oxacillinase gene bla OXA-58 in Acinetobacter baumannii. Antimicrob Agents Chemother 2006, 50: |442-1448.

10. Turton JF, Ward ME, Woodford N, Kaufmann ME, Pike R, Livermore DM, Pitt TL: The role of ISAbal in expression of OXA carbapenemase genes in Acinetobacter baumannii. FEMS Microbiol Lett 2006, 258:72-77.

II. Mugnier PD, Poirel L, Nordmann P: Functional analysis of insertion sequence ISAbaI, responsible for genomic plasticity of Acinetobacter baumannii. J Bacteriol 2009, 191:24|4-24I8.

12. Adams-Haduch JM, Paterson DL, Sidjabat HE, Pasculle AW, Potoski BA, Muto CA, Harrison LH, Doi Y: Genetic basis of multidrug resistance in Acinetobacter baumannii clinical isolates at a tertiary medical center in Pennsylvania. Antimicrob Agents Chemother 2008, 52:3837-3843.

13. Qi C, Malczynski M, Parker M, Scheetz MH: Characterization of genetic diversity of carbapenem-resistant Acinetobacter baumannii clinical strains collected from 2004 to 2007. J Clin Microbiol 2008, 46: I I06-II 09 .

14. Hujer KM, Hujer AM, Hulten EA, Bajaksouzian S, Adams JM, Donskey CJ, Ecker DJ, Massire C, Eshoo MW, Sampath R, Thomson JM, Rather PN, Craft DW, Fishbain JT, Ewell AJ, Jacobs MR, Paterson DL, Bonomo RA: Analysis of antibiotic resistance genes in multidrug-resistant Acinetobacter sp. isolates from military and civilian patients treated at the Walter Reed Army Medical Center. Antimicrob Agents Chemother 2006, 50:4II4-4I23.

15. Valentine SC, Contreras D, Tan S, Real LJ, Chu S, Xu HH: Phenotypic and molecular characterization of Acinetobacter baumannii clinical isolates from nosocomial outbreaks in Los Angeles County, California. J Clin Microbiol 2008, 46:2499-2507.

16. Bratu S, Landman D, Martin DA, Georgescu C, Quale J: Correlation of antimicrobial resistance with beta-lactamases, the OmpA-like porin, and efflux pumps in clinical isolates of Acinetobacter baumannii endemic to New York City. Antimicrob Agents Chemother 2008, 52:2999-3005.

17. Scott P, Deye G, Srinivasan A, Murray C, Moran K, Hulten E, Fishbain J, Craft D, Riddell S, Lindler L, Mancuso J, Milstrey E, Bautista CT, Patel J, Ewell A, Hamilton T, Gaddy C, Tenney M, Christopher G, Petersen K, Endy T, Petruccelli B: An outbreak of multidrugresistant Acinetobacter baumannii-calcoaceticus complex infection in the US military health care system associated with military operations in Iraq. Clin Infect Dis 2007, 44: I577-I584

18. Talbot GH, Bradley J, Edwards JE Jr, Gilbert D, Scheld M, Bartlett JG: Bad bugs need drugs: an update on the development pipeline from the Antimicrobial Availability Task Force of the Infectious Diseases Society of America. Clin Infect Dis 2006, 42:657-668.

19. Wertz JE, Goldstone C, Gordon DM, Riley MA: A molecular phylogeny of enteric bacteria and implications for a bacterial species concept. J Evol Biol 2003, 16:1236-1248.

20. Clinical and Laboratory Standards Institute: Methods for dilution antimicrobial susceptibility tests for bacteria that grow aerobically; approved standard. CLSI document. M7-A7. Wayne PA. USA 2006, 26-2:

21. Centers for Disease Control and Prevention: Standardized molecular sub typing of food borne bacterial pathogens by pulsedfield gel electrophoresis: a manual. National Center for Infectious Diseases, Centers for Disease Control and Prevention. Atlanta Ga. USA; 2000.

22. Cattoir V, Poirel L, Rotimi V, Soussy CJ, Nordmann P: Multiplex $P C R$ for detection of plasmid-mediated quinolone resistance qnr genes in ESBL-producing enterobacterial isolates. J Antimicrob Chemother 2007, 60:394-397.

23. Aminov RI, Chee-Sanford JC, Garrigues N, Teferedegne B, Krapac IJ, White BA, Mackie RI: Development, validation, and application of PCR primers for detection of tetracycline efflux genes of Gram-negative bacteria. Appl Environ Microbiol 2002, 68:1786-1793.

24. Hu WS, Yao SM, Fung CP, Hsieh YP, Liu CP, Lin JF: An OXA-66 OXA-5I-like carbapenemase and possibly an efflux pump are associated with resistance to imipenem in Acinetobacter baumannii. Antimicrob Agents Chemother 2007, 5 I:3844-3852.
25. Héritier C, Poirel L, Nordmann P: Cephalosporinase overexpression resulting from insertion of ISAbal in Acinetobacter baumannii. Clin Microbiol Infect 2006, I 2:123-130.

26. Sambrook J, Fritsch EF, Maniatis T: Molecular cloning: a laboratory manual. 2nd edition. New York: Cold Spring Harbor Laboratory Press; 1989.

27. Srinivasan VB, Virk RK, Kaundal A, Chakraborty R, Datta B, Ramamurthy T, Mukhopadhyay AK, Ghosh A: Mechanism of drug resistance in clonally related clinical isolates of Vibrio fluvialis isolated in Kolkata, India. Antimicrob Agents Chemother 2006, 50:2428-2432.

28. Beyer R, Pestova E, Millichap J], Stosor V, Noskin GA, Peterson LR: A convenient assay for estimating the possible involvement of efflux of fluoroquinolones by Streptococcus pneumoniae and Staphylococcus aureus: evidence for diminished moxifloxacin, sparfloxacin, and trovafloxacin efflux. Antimicrob Agents Chemother 2000, 44:798-80I.

29. Magnet S, Courvalin P, Lambert T: Resistance-nodulation-cell division-type efflux pump involved in aminoglycoside resistance in Acinetobacter baumannii strain BM4454. Antimicrob Agents Chemother 200I, 45:3375-3380.

30. Marchand I, Damier-Piolle L, Courvalin P, Lambert T: Expression of the RND-type efflux pump AdeABC in Acinetobacter baumannii is regulated by the AdeRS two-component system. Antimicrob Agents Chemother 2004, 48:3298-3304.

31. Bogaerts P, Cuzon G, Naas T, Bauraing C, Deplano A, Lissoir B, Nordmann P, Glupczynski Y: Carbapenem-resistant Acinetobacter baumannii isolates expressing the bla $a_{O X A-23}$ gene associated with ISAba4 in Belgium. Antimicrob Agents Chemother 2008, 52:4205-4206.

32. Poirel L, Figueiredo S, Cattoir V, Carattoli A, Nordmann P: Acinetobacter radioresistens as a silent source of carbapenem resistance for Acinetobacter spp. Antimicrob Agents Chemother 2008, 52:1252-1256.

33. Segal H, Jacobson RK, Garny S, Bamford CM, Elisha BG: Extended 10 promoter in ISAba-I upstream of bla oxA-23 from Acinetobacter baumannii. Antimicrob Agents Chemother 2007, 5 I:3040-304I.

34. Perez F, Hujer AM, Hujer KM, Decker BK, Rather PN, Bonomo RA: Global challenge of multidrug-resistant Acinetobacter baumannii. Antimicrob Agents Chemother 2007, 5 I:347I-3484.

35. Gombac F, Riccio ML, Rossolini GM, Lagatolla C, Tonin E, Monti-Bragadin C, Lavenia A, Dolzani L: Molecular characterization of integrons in epidemiologically unrelated clinical isolates of Acinetobacter baumannii from Italian hospitals reveals a limited diversity of gene cassette arrays. Antimicrob Agents Chemother 2002, 46:3665-3668.

36. Nemec A, Dolzani L, Brisse S, Broek P van den, Dijkshoorn L: Diversity of aminoglycoside-resistance genes and their association with class I integrons among strains of pan-European Acinetobacter baumannii clones. I Med Microbiol 2004, 53: 1233 - 1240.

37. Nemec A, Krízová L, Maixnerová M, Diancourt L, Reijden TJ van der, Brisse S, Broek P van den, Dijkshoorn L: Emergence of carbapenem resistance in Acinetobacter baumannii in the Czech Republic is associated with the spread of multidrug-resistant strains of European clone II. I Antimicrob Chemother 2008, 62:484-489.

Publish with Bio Med Central and every scientist can read your work free of charge

"BioMed Central will be the most significant development for disseminating the results of biomedical research in our lifetime. "

Sir Paul Nurse, Cancer Research UK

Your research papers will be:

- available free of charge to the entire biomedical community

- peer reviewed and published immediately upon acceptance

- cited in PubMed and archived on PubMed Central

- yours - you keep the copyright
BioMedcentral 